\title{
The Word, The Spirit, and The Action
}

\section{S.W.A. Gunn, MD, MS}

President

World Association for Disaster and Emergency Medicine

Medicine is a profession of curing and caring, but it also is a profession of teaching and learning. From its very beginnings in the hands of empirical shamans, later under the keen observations of Hippocrates, and nearer our times, in the testing laboratories of research, medical knowledge has been growing, branching out, and spreading through the teacher's word, the experimenter's figures, and the writers literature.

No science, and less so medicine, can advance without its literature, and in our field, Prebospital and Disaster Medicine (PDM) has firmly established itself as the prime source of scientific information on catastrophic emergencies and disaster situations, where the first consideration is to help man, whether an individual trauma case or-unfortunately-thousands of casualties. The more than 100 abstracts of thought-provoking papers in this issue from all parts of the world are an eloquent demonstration of the breadth and depth of our fast-developing field of action, action to which our Association is fully devoted.

A milestone that this issue of PDM highlights is the 20th. Anniversary of the World Association for Disaster and Emergency Medicine (WADEM)indeed more or less the 20 years of concept of Disaster Medicine as a distinct activity. This is a justifiable occasion for celebratory cheer and scientific reflection, and it pleases this writer to think that the reader of these pages may be savoring its contents in the city of Mainz, where WADEM started two decades ago by a group of visionaries and, more significantly, where printing began with Gutenberg several centuries earlier.
Reflection over our past also calls for scientific ponderation and professional satisfaction. We have been key instruments in establishing Disaster Medicine as a specialty; we have strengthened the concept of mass Emergency Medical Services; we have consolidated our position as the prime Association worldwide that promotes excellence at every stage of dealing with major emergencies and disasters; and we have woven friendships and professional ties in all parts of this fragile spaceship Earth. I should like to add to these achievements another fundamental development that gives me particular satisfaction: that of the imperative inclusions and growth of the humanitarian element in all our work. WADEM has been a pioneer in spearheading the idea $^{l}$ of Humanitarian Medicine, and it is with humility and pride that we note this to have become reality not only within our Association, but also, and significantly, at the World Health Organization and at the United Nations.

With this scientific and moral maturation goes a more practical growth by which the Association has expanded in numbers, has become more active, has attracted the kindred professionals, and is now the sole publisher of Prehospital and Disaster Medicine, the profession's only scientific forum which has become obligatory reading for the dissemination of knowledge in our specialty. WADEM also particularly welcomes the 10 other affiliated organizations from many parts of the world that consider $P D M$ their umbrella journal, and negotiations are under way to share our columns with other like-minded societies.

So we go forward to our third decade -and the third millennium-wellarmed and well-established. I am particularly pleased that Steve Rottman will lead the Association and Marvin Birnbaum will ensure the editorship of the journal during this period. With their heads in academia and their feet firmly set on applied terrain, these two scientist should take us to even higher sights and to more fruitful activities, a point of faith I fully share as I celebrate my 20 years' ties with this wonderful association of humanitarian action that started as the Club of Mainz and which goes forward as the World Association for Disaster and Emergency Medicine. 